\title{
PROPOSAL OF A TESTING PROGRAM FOR THE HP14 (ECOTOXIC) CLASSIFICATION OF AUTOMOTIVE SHREDDER RESIDUES (ASR) BY A BATTERY OF ECOTOXICOLOGICAL BIOASSAYS
}

\author{
Alberto Pivato ${ }^{1}$, Giovanni Beggio ${ }^{1, \star}$, Pierre Hennebert ${ }^{2}$, Tiziano Bonato ${ }^{3}$, Martina Favarin ${ }^{1}$ \\ and Roberto Raga ${ }^{1}$
}

${ }^{1}$ Department of Civil, Environmental and Architectural Engineering, University of Padova, Via Marzolo 9, 35131, Padova, Italy

2 INERIS, French National Institute for Industrial and Environmental Risks, CS 10440, 13592 Aix-en-Provence. Cedex 04, France

${ }^{3}$ Chemical consultant, Italy

Article Info:
Received:
24 October 2019
Revised:
7 July 2020
Accepted:
31 July 2020
Available online:
30 November 2020
Keywords:
Ecotoxicity
HP 14
Test battery
Leaching Test
Automotive Shredder Residues

\begin{abstract}
This manuscript describes a full procedure to be used in performing HP 14 classification of Automotive Shredder Residue (ASR). Sampling instructions and conditions for the transport and storage of ASR samples are included. Additionally, the steps to be followed in preparation of test portions (both solid samples and water extracts) prior to chemical characterization and subsequent ecotoxicological testing are defined. The established test battery includes all bioassays proposed in Pandard and Römbke (2013). Only aquatic bioassays are proposed as mandatory in this paper, which leaves the possibility of performing tests on terrestrial organisms based on the results of chemical characterization of the solid samples. Finally, the proposed set of concentration limits triggering HP 14 classification is fully consistent with thresholds described by Hennebert (2018a).
\end{abstract}

\section{INTRODUCTION}

Ecotoxicity is acknowledged as the most frequent property classifying wastes as hazardous (Hennebert et al, 2014). In Europe, wastes are classified for ecotoxicity (HP 14) according to the Regulation 2017/997/EC (European Parliament and European Council, 2017). The latter introduces a calculation method for the HP 14 classification, based solely on chemical concentrations of the hazardous substances occurring in the waste to be classified (i.e., classified with a Hazard Statement Code (HSC) H400, $\mathrm{H} 410, \mathrm{H} 411, \mathrm{H} 412$ and/or H413) according to the Regulation on Classification, Labeling and Packaging of Products and Substances 2008/1278/EC (European Parliament and European Council, 2008a). However, it does not include any specific guidance for performing the HP 14 classification through ecotoxicological testing. At the same time, it states that each Member State can adopt specific analytical protocols on conducting bioassays and the derived outcomes supersede results from chemical composition analyses.

The lack of a clearly established testing procedure can lead to erroneous waste classifications of those waste streams typically classified as mirror entries by the European Waste Catalogue (EWC), which must be declared as hazardous based on mandatory compliance assessment (European Commission, 2000).

For this reason, the objective of this paper is to propose a testing procedure allowing for a complete HP 14 classification of a classic example of a mirror entry, (i.e., Automotive Shredder Residues (ASR)), which is classified in the EWC with the couple of codes 1910 03* (hazardous) and 191004 (non hazardous). Therefore, ASR is here intended as the so-called "light fluff", which is the lighter fraction separated through air classification from the shredded hulk (Cossu et al., 2014). ASR is a highly heterogeneous waste stream, both in terms of granulometry and materials composition: it includes plastic, foam, textiles and metallic (magnetic, non-magnetic and PVC covered cables) particles, characterized by broad size distribution (Cossu and Lai, 2015). Significant environmental issues related to ASR management could arise due to the reported presence of trace elements, heavy metals and possible organic contaminants (i.e. PAHs, PCBs and mineral oil) (Cossu et al, 2014).

The choice of addressing HP 14 classification for this 
specific kind of waste was based on opportunity. However, the rationale behind this proposal can be applied to other mirror entries by taking care of fine tuning this procedure according to observable specific features. These specific features mainly relate to sampling and analytical procedures (e.g., particles size distribution and size reduction, extreme values of $\mathrm{pH}$ in the water extracts, and the need to investigate the presence of specific contaminant concentration).

This paper also includes detailed instructions about sampling, transport and storage of ASR laboratory samples. Furthermore, it describes stepwise procedures for liquid and solid test portion preparation, which will undergo further chemical analysis and ecotoxicological characterization. Also, the rationale behind the various requirements is explained. Elements of the whole procedure were not proposed from scratch but reference both to specific international and European technical standards as well as European ongoing regulations.

Regulation 2017/997/EC considers as the appropriate biotest procedures the ones which are consistent with the relevant methods established in the Regulation 2008/440/EC, pursuant to the Regulations 2006/1907/EC and 2008/1272/EC on products and substances (naming REACH and CLP, respectively), or "other internationally recognized test methods and guidelines" (European Parliament and European Council, 2006, 2008a, 2008b, 2017). In particular, the proposed ecotoxicological test battery includes all bioassays proposed in Pandard and Römbke, (2013). Therefore, the compliance with Regulation 2017/997/EC is assumed according to the fact that the chosen approach relies on technical standards referring to internationally acknowledged EN ISO series.

The CLP Regulation classifies products and substances (both liquid and solid) only for ecotoxicity in aquatic environment, thus requiring only chemical characterization on the water extracts or biotests performed on aquatic organisms. Although, chemical investigations on solid samples and bioassays carried out on terrestrial organisms could assess the presence of contaminants able to bind to soil particles and related exposure pathways, this behavior cannot be investigated solely by analyses on liquid samples (e.g. non-soluble or non-leachable substances). Given this background as well as considering the principle of the technical and economic feasibility as sanctioned by the Directive 2008/98/EC (European Parliament and European Council, 2008,b), the authors propose to include a chemical characterization of solid waste, which can trigger the need to assess related toxicity patterns through specific terrestrial ecotoxicity testing. In this context, ecotoxicological tests and chemical characterization are assumed to act not independently but synergistically for waste classification.

Lastly, the classification criteria of the results from bioassays were derived based on the concentration limits listed in Hennebert, (2018), which were proposed consistently with the EWC. The authors acknowledge that the EWC is not fully based on scientific evidence, as it is partly the result of political compromises and lobbying. Nevertheless, it is currently the only source which can be used as a reference for classification purposes.

\section{METHODOLOGY}

\subsection{General Procedure}

The general objective of the proposed testing program is to assess the classification of ASR as hazardous by HP 14. The consequent level of testing is the compliance testing level. The different phases of the proposed experimental protocol are outlined in the flowchart depicted in Figure 1. The stepwise procedure starts from the sampling phase, which is aimed at producing two laboratory samples that would be assessed by fractional composition analysis and chemical- ecotoxicological characterization, respectively. The obtained samples are then transported and stored in the laboratory where analyses will be performed. One laboratory sample undergoes Fractional Composition Analysis without any further preparation steps. Then, the solid test portion is prepared from the other laboratory sample to undergo i) chemical characterization and ii) leaching testing aimed at obtaining the relative water extracts. Chemical characterization and aquatic bioassays are then performed on the resulting aqueous test samples (i.e., water extracts). Terrestrial bioassays completed on the solid test samples are only executed if the results of the chemical characterization are not compliant with the proposed concentration limits for solid samples (outlined in Table 3). Finally, the ASR sample is classified for HP 14 based on the results of the comparison between the proposed concentration limits and the obtained results from the performed aquatic (Table 4) and terrestrial (Table 5) bioassays.

The rationale behind the requirements described for each phase of the proposed procedure is illustrated in the following sections.

\subsection{Sampling, Transport and Storage}

The proposed protocol defines a Sampling Plan consistent with the standards outlined in EN 14899:2015, UNI EN 10802:2013, and EN 15002:2015. Furthermore, instructions for Transport and Storage are consistent with EN 14735:2005.

If possible, it is recommended that sampling is performed by picking up the material dynamically from the conveyor belt placed downstream of the occurring aeraulic classifier. This approach is recommended to minimize spatial segregation due to the possible differential gravity settling occurring in the waste heap configuration. If dynamic sampling cannot be accomplished, sampling actions should be performed statically, either by stopping the conveyor belt or by carrying out sampling from temporary storage (heap configuration). Subsampling should be performed according to the "quartering and coning" procedure as explained in EN 15002:2015. Also, the so-called "long pile procedure" can be equivalently performed for the reduction of sample mass, according to EN ISO 14780:2017.

The calculation method used, and the parameters values assumed to determine the minimum sample mass of both primary sample and laboratory sample is described in Paragraph SM.1 of the Supplementary Material. Different values should be justified according to the results of further material investigations (e.g. bulk density) or granulometric analyses (e.g. definition of alternative D95) per- 


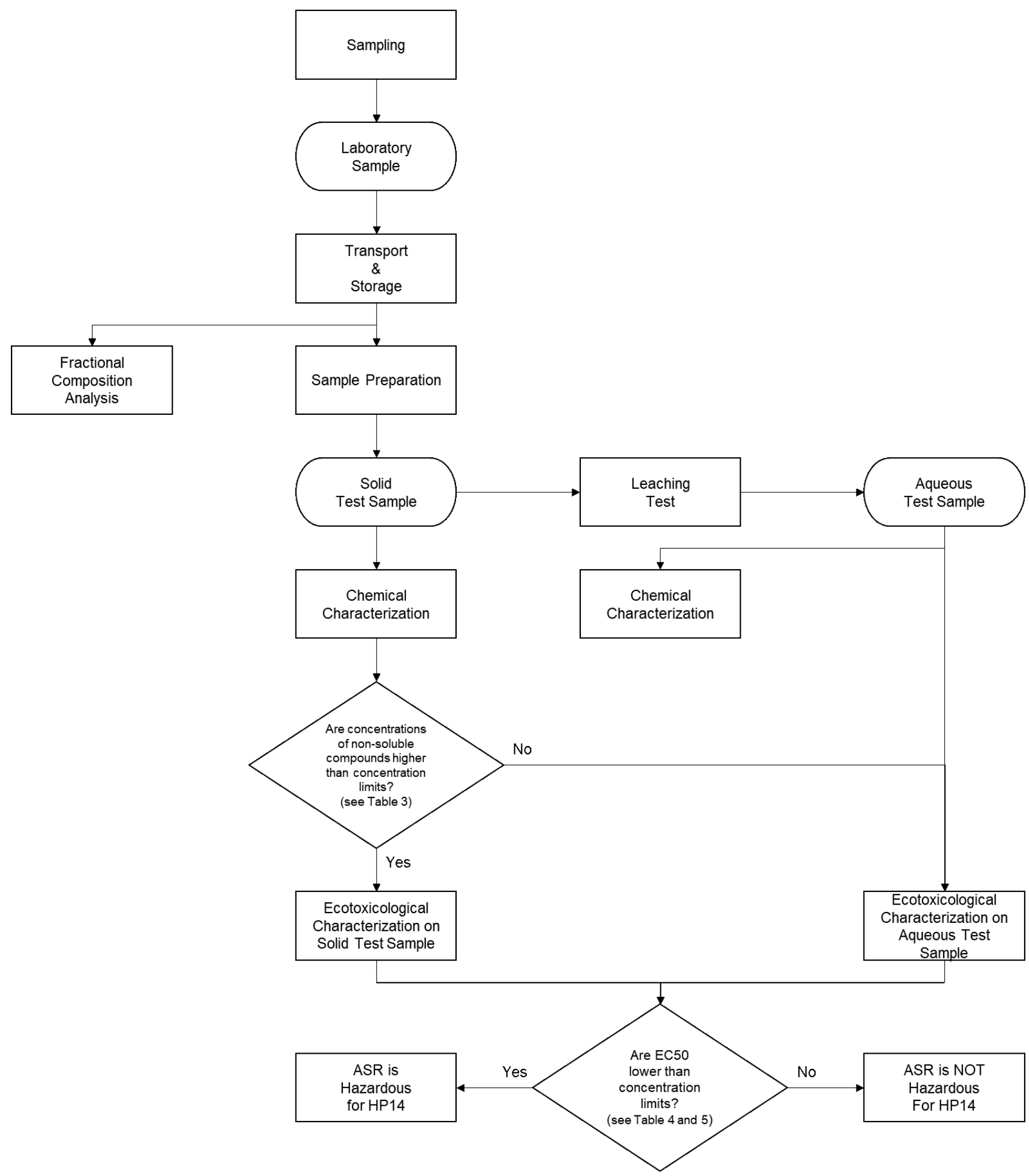

FIGURE 1: Stepwise procedure for HP14 classification of Automotive Shredder Residues (ASR).

formed on untreated sample (i.e., not size reduced). Here, ASR can be characterized by the presence of fines $(0-20$ $\mathrm{mm})$ up to $70 \%(\mathrm{w} / \mathrm{w})$ of the total sample, which can significantly lead to overestimation of the size of the laboratory sample (Cossu et al, 2014).

\subsection{Fractional Composition Analysis}

Fractional composition analysis is included in the pro- cedure in order to determine the different material fractions making up the laboratory sample. Results of the fractional composition analysis are used to determine qualitatively the composition of the resulting laboratory sample and will not be used for any compliance assessments. This assumption allows us to perform such analysis on test portions which cannot be considered representative because of the suggested sample size. 


\subsection{Test Samples Preparation - Leaching Test}

Instructions for the preparation of solid test samples are consistent with the principles reported in EN 15002:2015 for chemical analysis and EN 14735:2005 for terrestrial bioassays. The leaching test procedure is proposed in line with EN 12457-2 to derive water extracts for chemical analysis and aquatic bioassays.

While there is an agreement on the leaching procedure to derive water extracts for chemical characterization (i.e. EN 12457-2, here adopted), two main approaches are acknowledged for the preparation of waste eluates for ecotoxicological testing, both related to specific standards:

1. EN 14735 - Characterization of waste - Preparation of waste samples for ecotoxicity tests (EN 14735, 2005, currently under revision). Here, ASR can be considered as "granular waste". Consequently, specific water extracts must be derived following the "leaching test" procedure as laid out in EN 12457-2:2004;

2. OECD Document, nr. 23 and OECD Document, nr. 29 Guidance on transformation/dissolution of metals and metal compounds in aqueous media. These standards are recalled by CLP Regulation (OECD, 2001, 2019).

Among the different requirements established by the cited standards (e.g. test duration, particle size), the factor most influencing the chemical profile of the obtained water extracts is the prescribed loading rate, $100 \mathrm{~g} / \mathrm{L}$ for EN $12457-2$ and $100 \mathrm{mg} / \mathrm{L}$ for OECD n.29. For the same amount of waste material, the consequent L/S ratios (10 L/ kg vs. 10.000 L/kg for EN 12457-2 and OECD n.29, respectively) mimic long term release conditions which differ of several orders of magnitude in terms of years of occurred percolation or contact with pore water. Consequently, EN 12457-2 led to water extracts characterized by higher inorganic chemical concentrations (e.g. Heavy Metals) compared to OECD Documents nr. 23 and 29, when applied on the same ASR samples (Pivato et al., 2019). In this situation, a water extract should likely be considered more relevant to aquatic organism when derived applying the lower L/S ratio as practically feasible (Van der Sloot et al., 1997, Van der Sloot and Dijkstra, 2004). Besides, the requirements laid down in EN 12457-2 results in a more operative process to prepare a representative test portion (i.e. less efforts for both size reduction and subsampling) (Pivato et al., 2019). Finally, chemical and ecotoxicological characterization conducted on eluates identically derived allow an integrated assessment (Van der Sloot and Dijkstra, 2004). For these reasons, the experimental protocol being proposed, adopts the EN 12457-2 for liquid sample preparation prior to chemical characterization and ecotoxicity testing.

\subsection{Chemical Characterization}

Chemical characterization of both solid sample and waste eluates should be conducted in triplicate to assess the representativeness of the derived solid test portions after the subsampling process. In fact, the analyzed solid test portions can be considered representative if the coefficients of variation, calculated for each measured parameter as standard deviation divided for the mean of concentration, is low enough low to represent the lowest possible degree of variability, i.e. due to the performed analytical protocol. In this context, a CV of 0.1 can be taken as a reference value (CEN, 2006, Hennebert, 2019).

Results of the bioassays prevail on the assessment based on liquid concentration data for the sake of HP 14 classification (European Parliament and European Council, 2017). In this context, chemical characterization of ASR aqueous samples could allow to evaluate the leachable fraction of inorganic compounds (e.g. HMs), which can be considered responsible for the effects on the aquatic organisms. In fact, liquid concentration data can be used to calculate element-specific Toxic Units, by dividing measured values by the respective EC50 values as found in scientific literature or ecotoxicological repositories, to help interpret the outcomes from bioassays. The list of parameters which should be assessed on ASR eluates could be taken by what is prescribed by European Council, (2003).

Conversely, chemical characterization of solid test samples is needed to investigate the presence of non-soluble compounds likely occurring in ASR, i.e. Mineral Oil, PAHs and PCBs, whose effect in terms of toxicity cannot be assessed through aquatic bioassays (Cossu et al, 2014). It should be highlighted that ASR (as any other mirror entry) could be classified as hazardous for HP 7 and HP 11 in case concentrations of substances, classified with carcinogenic HSCs, are reported over specific thresholds established by specific regulations (European Commission, 2014). Therefore, the presence of one of the listed substances below the lowest thresholds specifically established by the regulations should trigger the need to perform the battery of terrestrial bioassays. In particular, the list of parameters which should be investigated in ASR solid test samples should include Mineral Oil (as Total Petroleum Hydrocarbons) i.e. sum of $\mathrm{C}<12$ and $\mathrm{C}>12$, PCBs and the list of $\mathrm{PAHs}$ required by the regulation (European Commission, 2014). This is reflected in the proposed protocol.

\subsection{Ecotoxicological Characterization}

The choice of the test battery has been determined following method proposed by Pandard and Römbke, 2013. Currently, there is consensus within the scientific community about this proposition, specifically when performed for fully comprehensive ecotoxicological characterization of waste (Moser and Römbke, 2009, Pandard and Römbke, 2013, Römbke, 2018). It should be assumed as a minimum set of assays, since it can be proved that the results from each ecotoxicological test will not be correlated with the other required tests, thus highlighting difference in the mechanisms of toxicity.

According to the principle of technical and economic feasibility (European Parliament and European Council, 2008b), each suggested bioassay should be performed on a unique test portion, constituted by the combination of three equal aliquots of the available test samples undergone chemical characterization (both solid and liquid).

The need to perform the set of terrestrial bioassays is triggered only if the derived concentration level of a defined list of substances in the solid test samples is not compliant with specific concentration limits proposed in national 
and international regulations.

\subsection{Criteria for HP 14 Classification of ASR}

The choice of concentration limits triggering the HP14 classification of the tested samples were established according to the proposition of Hennebert (2018a and $2018 \mathrm{~b})$. At the time of developing this approach, the proposed set of concentration limits were not applied in the national or international regulations. However, what is proposed in Hennebert, (2018) is currently the only available set of limits which can consistently be compared with the results of the proposed test battery, when performed according to the cited international guidelines (from EN ISO series, e.g. EN ISO 11348-3, EN ISO 8692 and EN ISO 6341).

\section{PROPOSED PROCEDURE FOR HP 14 CLAS- SIFICATION OF ASR}

\subsection{ASR Sampling}

- The technical goals of the sampling plan should be:

1. the production of a laboratory sample representative of ASR regularly produced in a specific treatment plant considering the potential variability of input materials and produced waste in terms of both composition and granulometry;

2. the production of a laboratory sample characterized by a sample size suitable, in terms of mass, to perform the planned analysis.

- To achieve the aforementioned technical goals, sampling of ASR is performed according to a probabilistic random sampling approach.

- The laboratory sample is obtained through a stepwise procedure:

1. Primary sample (i.e. composite sample) production, and

2. Quartering procedure.

- Two sampling techniques can be performed to obtain the primary sample:

1. Sampling from temporary storage (see Paragraph 3.1.1);

2. Sampling from a conveyor-belt (see Paragraph 3.1.2).

- The proposed methodology ensures that the laboratory samples are representative in terms of both quality and composition of each part of a monthly produced amount of ASR.

- A primary sample must be characterized by a total fresh mass of about $1.300 \pm 50 \mathrm{~kg}$.

- At the end of the quartering procedure, the laboratory sample which will undergo chemical and ecotoxicological characterization should be characterized by a total fresh mass of $30 \pm 5 \mathrm{~kg}$. The obtained laboratory sample should be characterized by a D $95 \leq 2 \mathrm{~cm}$. Therefore, on-site size reduction (e.g. through portable shredding equipment) could be needed before performing the Quartering procedure.

- At the end of the quartering procedure, the laboratory sample which will undergo fractional composition analysis should be characterized by a total fresh mass of $60 \pm 5 \mathrm{~kg}$ and should not undergo any size reduction for any reason.

- Different mass values for both primary and laboratory samples should be justified according to the results of further material investigations (e.g. bulk density) or granulometric analyses (e.g. definition of alternative D95) performed on untreated sample (i.e., not size reduction).

- Paragraph SM.2 of the Supplementary Material contains the minimum set of information that the sampling operator should complete and send to the laboratory with the collected sample.

\subsubsection{Sampling from temporary storage}

- A primary sample from a temporary storage heap must be performed monthly.

- The primary sample is a composite sample obtained by mixing together at least 20 increments, withdrawn from the ASR storage heap. Each increment must be characterized by a minimum increment weight of about $65 \mathrm{~kg}$ (i.e. $1.300 \mathrm{~kg}$ divided by 20 increments). It is preferred that increments are withdrawn with a mechanical bucket. Otherwise, increments should be collected using a shovel characterized by an opening size of at least $30 \mathrm{~cm}$.

- Increments must be taken from the temporary ASR storage at different heap heights (see Figure 2 for examples of sampling locations based on heap subdivision). At least 3,7 , and 10 samples must be taken from the top, medium, and bottom layers of the heap, respectively. Additional increments could be obtained but care must be taken to maintain a ratio of 2:4:6 between increments withdrawn from the top, medium, and bottom layers, respectively. Each layer must be characterized by approximately the same height.

- The primary sample is then obtained after homogenizing (e.g., through mixing with shovels) the increments collected.

\subsubsection{Sampling from conveyor-belt}

- A primary sample from the conveyor belt must be collected monthly.

- The primary sample is a composite sample obtained by mixing together at least 20 increments, withdrawn from the conveyor belt during normal daily operations. Each increment must be characterized by a minimum size of about $65 \mathrm{~kg}$ (i.e. $1.300 \mathrm{~kg}$ divided by 20 increments).

Each increment is sampled directly from the conveyor belt (during normal operation) preferably by use of cross stream sampler. Otherwise, a container can be used with enough of a capacity (i.e., characterized by an opening size of at least $30 \mathrm{~cm}$ ), handled by a lifter, ensuring that a constant velocity is maintained through all the cross section of the conveyor belt.

\subsubsection{Quartering procedure}

- The production of the laboratory sample is achieved according to the so-called quartering procedure, as follows (Figure 3):

I. Distribution of the primary sample of ASR on a cemented pavement and formation of a circular cake; 


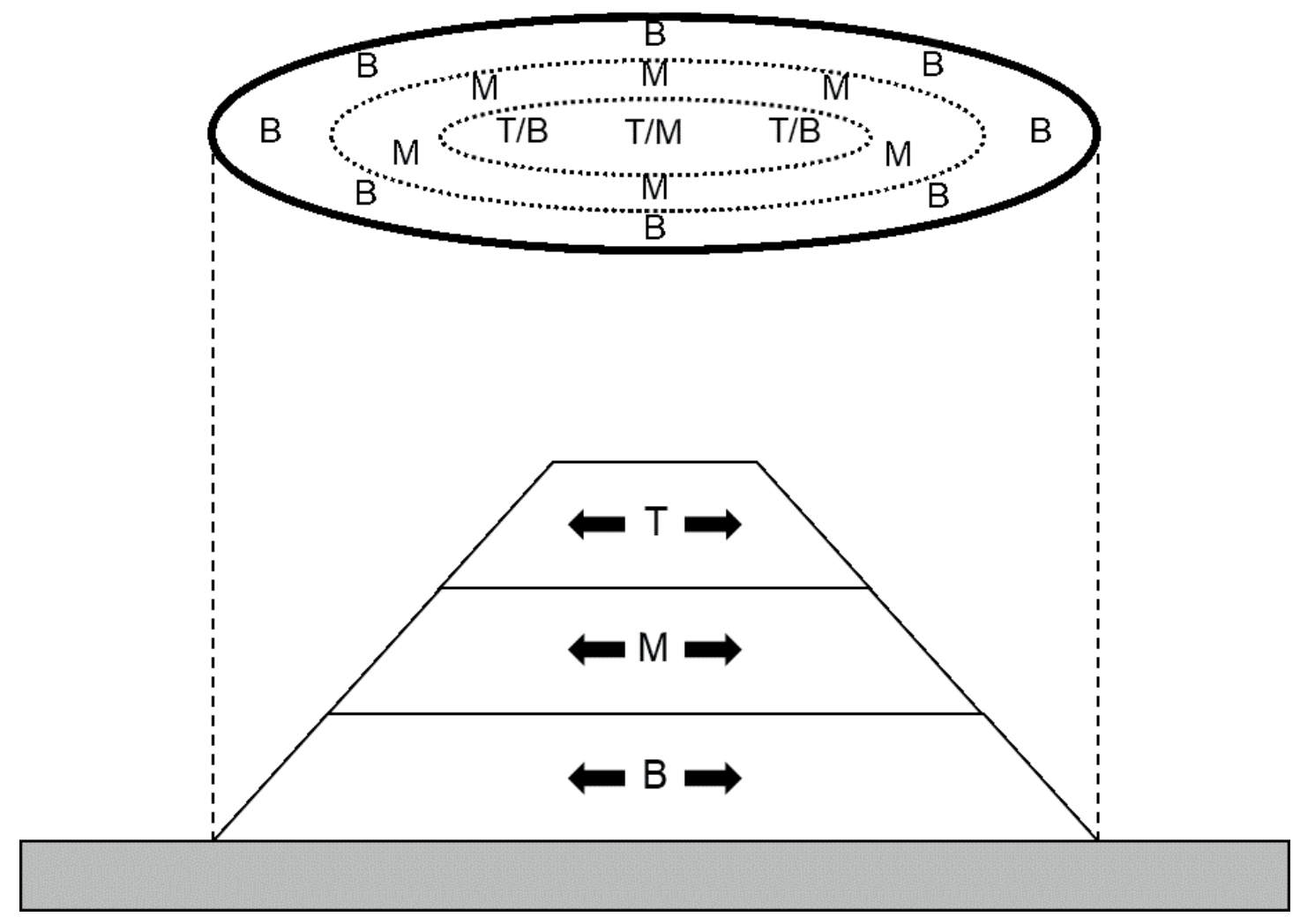

FIGURE 2: Schematization of ASR storage heap subdivision for increments withdrawal ( $T=$ Top layer, $M=$ medium layer, $B=B$ ottom layer).

II. Superficial subdivision with two perpendicular diametrical lines and complete removal of the material belonging to two opposite quadrants with a shovel and broom;

III. Mixing of the ASR from the remaining quadrants and formation of a new circular cake;

IV. Superficial subdivision with two orthogonal diameters, displaced by $45^{\circ}$ with respect to the two previous tracers and complete removal of the material belonging to two opposite quadrants with a blade and broom;

V. Mixing of the remaining parts (i.e., about a quarter of the original one) and formation of a cake, ensuring to maintain approximately the same layer thickness while reducing the overall diameter;

VI. On the new circular cake, the same steps carried out previously on the initial cake are iterated enough times so that with the last quartering results in a sample characterized by a weight of $30 \pm 5 \mathrm{~kg}$, which is defined as the "laboratory sample".

- Instead of the quartering procedure as here described, the "long pile" procedure can be performed equally for the reduction of mass of the primary sample, according to EN 14780:2017.

\subsection{Transport and storage}

\subsubsection{Transport}

- The laboratory samples should be sent to the laboratory and stored in a resealable container that also ensures that the samples are kept in dark conditions.
- The container material shall be appropriate and not be a cause any type of contamination.

- Transport times of the laboratory samples should be as short as possible. Transport times shall be included in the overall storage time. A transport time of less than $12 \mathrm{~h}$ under refrigerated conditions $(4 \pm 2)^{\circ} \mathrm{C}$ shall be maintained in order to preserve the original properties of the laboratory samples and to avoid the migration of volatile fractions. If it is demonstrated that volatile compounds are not present in the sample, different transportation conditions can be permitted.

\subsubsection{Storage}

- Storage should be carried out in the same containers used for transport. Possible changes may be considered, and storage conditions shall be designed accordingly in order to limit the effects of such changes on the results of any tests. Any applicable changes must be reported in the final test report;

- Storage time starts from the collection of laboratory samples and ends with the start of definitive tests and should be as short as possible;

- A storage time of less than two months and at low temperature conditions $(4 \pm 2){ }^{\circ} \mathrm{C}$ shall be established in order to appropriately maintain the properties of the waste samples.

\subsection{Fractional composition analysis}

Fractional composition analysis is performed according to the following stepwise procedure: 


\section{Primary sample \\ $1.300 \mathrm{~kg}$ \\ ת}

\section{SIZE REDUCTION}

(if primary sample is characterized by a $\mathrm{D} 95 \geq 1 \mathrm{~cm}$ )

$1.300 \mathrm{~kg}$

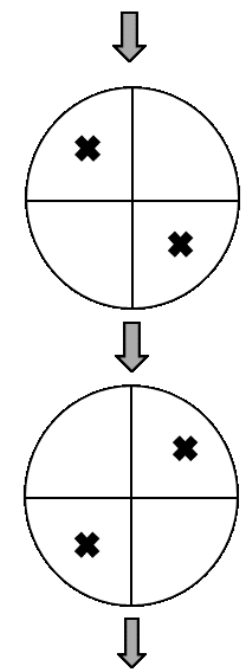

$1^{\circ}$ cake

$\sim 650 \mathrm{~kg}$

$\sim 60 \mathrm{~kg}$

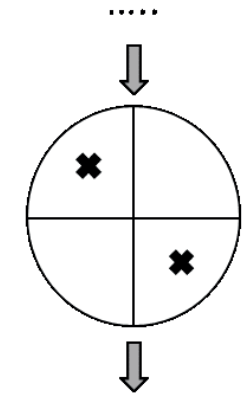

Laboratory sample

$\sim 30 \mathrm{~kg}$

FIGURE 3: Quartering procedure for the preparation of the final laboratory sample (derived from EN 15002:2013).

I. Three test portions of about $20 \mathrm{~kg}$ are obtained through the quartering and coning procedure from the subsample derived from the previous step. No size reduction processes are performed on the 3 derived test portions;

II. Each obtained test portion is sieved through a 20 $\mathrm{mm}$ sieve;

III. The over-sieve fraction is divided into different categories (e.g., plastic foam and rubber, metals, cellulosic materials (wood and paper), textiles, electric cables, composites, and undersieve $<20 \mathrm{~mm}$ );

IV. Each fraction is weighed to determine the specific weight percentages;

- The analysis is performed in triplicate, (i.e., 3 test portions (in total $3 * 20 \mathrm{~kg}=60 \mathrm{~kg}$ ));

- An example of the report table to complete while performing the analysis and a exemplificatory figure for the graphical representation of the results are included in Paragraph SM. 3 in the Supplementary Material.

\subsection{Preparation of test samples for chemical and ecotoxicological analysis}

- Chemical analyses are performed on the following samples:

- ASR solid test samples (see Paragraph 3.5.1), and

- ASR aqueous test samples which are derived from the leaching procedure (see Paragraph 3.5.2).

- Ecotoxicological Analyses are performed on a defined mixture of a dilution media (as required by each selected bioassay) and:

- ASR solid test samples for terrestrial tests (see Paragraph 3.6.1), or

- ASR aqueous test samples for aquatic tests, derived from a leaching procedure performed on the solid test portion of the ASR subsamples (see Paragraph 3.6.2).

\subsubsection{Solid test sample preparation}

The preparation of the solid test sample is a stepwise process: each phase must be performed according to the following approach:

I. A subsample of the laboratory sample, characterized by a weight of about $15 \mathrm{~kg}$, must be obtained through a quartering and coning procedure.

II. Non-crushable material occurring in the subsample characterized by a particle size $>4 \mathrm{~mm}$ (e.g. metallic parts such as nuts, bolts, scrap) that can possibly damage crushing equipment, must be selected and removed from the subsample before size reduction occurs. The particles withdrawn must be reported and classified according to the material composition and weight. The removed fraction should not exceed $10 \%$ (mass) of the total aliquot of the sample considered, otherwise the selected subsample must be discarded.

III. At least $95 \%$ (on a weight base) of the ASR test sample must be characterized by a grain size of less than $4 \mathrm{~mm}$. If oversized (i.e. grain size $>4 \mathrm{~mm}$ ) materials exceed $5 \%$ (on a weight base), the oversized materials must be reduced in size with an appropriate crushing apparatus (e.g. shredder). Materials with a high particle size (e.g., plastic foam, long electric cables, bigger pieces of textiles) can be cut with other kinds of manual or mechanical devices prior to crushing, in order to avoid blockages of the crushing equipment.

IV. Place the size-reduced subsamples within a container of adequate capacity and mix carefully with an appropriate tool (e.g. shovel, scoop, or trowel).

$\mathrm{V}$. The size of the prepared test samples must be determined according to the need of the following analytical determinations. Therefore, the needed test samples are:

- Test sample (about $300 \mathrm{~g} \mathrm{TS}$ ) for aqueous test sample preparation through a leaching test (see Paragraph 7.2)

- Test sample (about $300 \mathrm{~g}$ TS) for chemical cha- 
racterization of $A S R$, and

- Test sample (the remaining amount of ASR test sample) for ecotoxicological characterization on terrestrial organisms.

\subsubsection{Aqueous test sample preparation - Leaching test}

Leaching test is performed in triplicate and according to the following stepwise procedure:

I. Place a solid ASR test portion characterized by a total dry mass of $90( \pm 5) \mathrm{g}$ TS (i.e., prepared according to Paragraph 9.1) in a glass container with a nominal volume of $2 \mathrm{~L}$.

II Add distilled water to reach $900 \mathrm{ml}$ of water including the moisture of the sample to ensure a liquidsolid ratio (L/S) of $10 \mathrm{~L} / \mathrm{kgTS} \pm 2 \%$.

III. Agitate the glass container containing the ASR solid test portion and the distilled water using an end-over-end tumbler at 5-10 rpm at room temperature $\left(15^{\circ} \mathrm{C}\right.$ to $\left.25^{\circ} \mathrm{C}\right)$ for $24 \pm 0,5 \mathrm{~h}$.
IV. Allow suspended solids to settle for 15-30 min and centrifuge the eluate for $30 \mathrm{~min}$ at $2500 \mathrm{~g}$, whether or not incomplete separation of solid and liquid phases occurs.

V. Filter the obtained eluate through a 0,45 $\mu \mathrm{m}$ membrane filter using a vacuum or pressure filtration device. Rinsing the filter is not permitted after filtration.

VI. Measure and report conductivity in $\mu \mathrm{S} / \mathrm{cm}$ (EN 10523:2012) and pH (ISO 10523:2008) of the resulting water extract immediately.

VII. Do not adjust the $\mathrm{pH}$ in any case during the leaching test procedure;

VIII. Take a subsample (e.g. 1/3 L) from each of the water extract replicates to reconstitute the test sample to be used in ecotoxicological bioassays on aquatic organisms.

IX. The required volume (in $\mathrm{ml}$ ) of the prepared test samples must be determined according to the

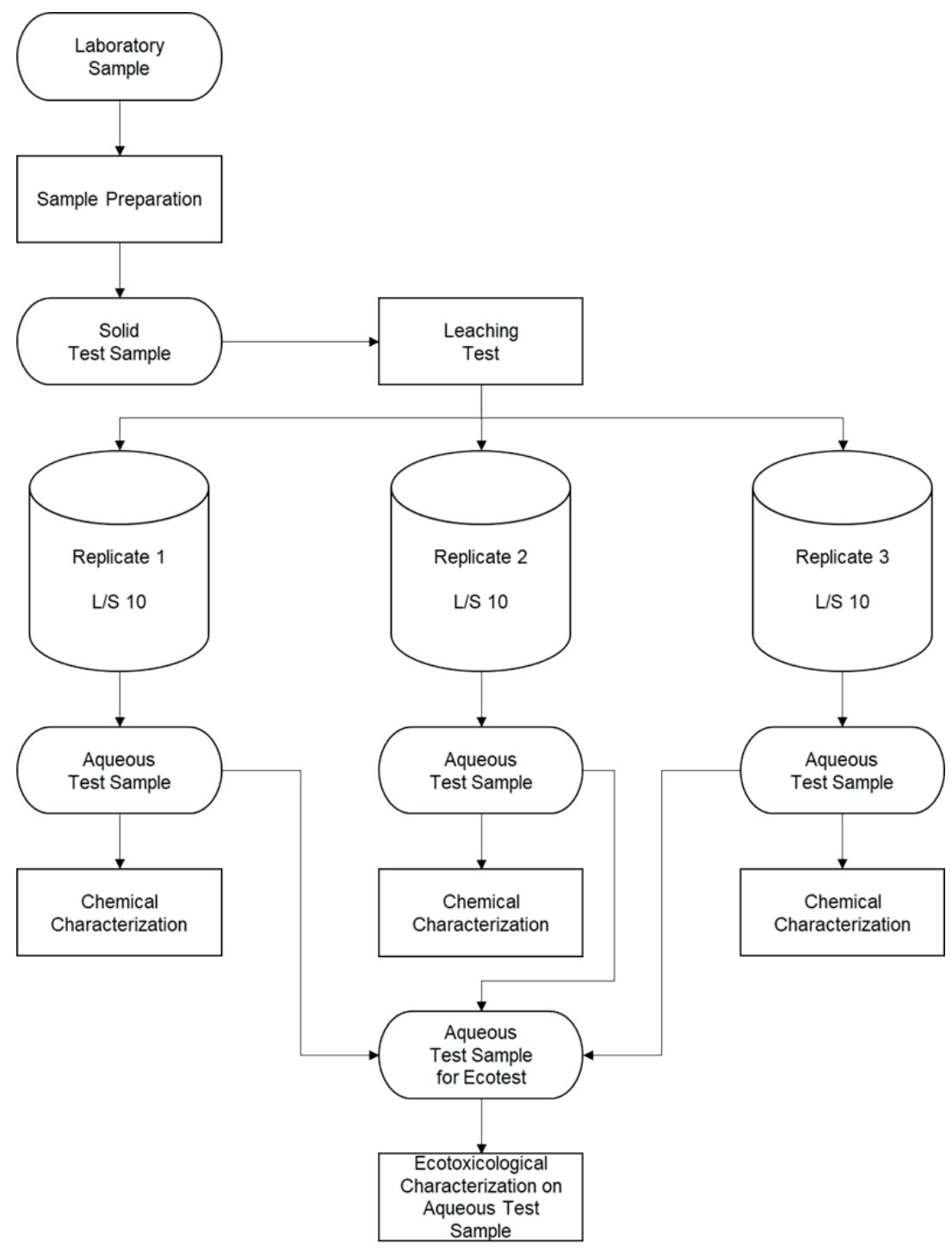

FIGURE 4: Detailed graphical procedure for deriving aqueous test samples through leaching tests for chemical and ecotoxicological analysis. 
requirements of the following analytical determinations. Therefore, the necessary amount of test samples are:

- Test sample (about $100 \mathrm{ml}$ for each water extract replicate) for chemical characterization;

- Test sample (about $400 \mathrm{ml}$ ) for ecotoxicological characterization of aqueous test sample reconstituted as described in step VIII.

- The proposed procedure is graphically described in Figure 4.

- Further details of the leaching procedure may be found in EN 12457-2 and EN 14735.

\subsection{Chemical characterization}

- Chemical Analysis are performed on:

- ASR solid test samples, and

- ASR aqueous test samples, (i.e., derived from a leaching procedure (see Paragraph 3.4.2)).

\subsubsection{Chemical characterization of ASR solid test sample}

Table 1 lists the chemical concentrations that must be measured in the prepared ASR solid test samples

Chemical analysis listed in Table 1 must be performed on 3 ASR test samples, where each one is characterized by an amount of $90( \pm 5) \mathrm{g} \mathrm{TS}$.

\subsubsection{Chemical characterization of ASR aqueous test sam-} ple

- The aqueous test samples, derived from each replicate leaching test (see Paragraph 3.4.2), must undergo chemical characterization for the parameters established in Table 2;

\subsection{Ecotoxicological characterization}

- Compare concentration values obtained from solid test samples (see Paragraph 3.5.1) with the concentration ranges listed in Table 3 . Whether at least one concentration values of non-soluble compounds is within the listed ranges, it will trigger the need to implement terrestrial bioassays. Otherwise, only aquatic test must be implemented.

- Results of ecotoxicological tests are expressed in

TABLE 1: List of parameters to be measured in solid test samples.

\begin{tabular}{|c|c|c|}
\hline Analytes & $\begin{array}{l}\text { Unit of } \\
\text { measure }\end{array}$ & Standards \\
\hline Total Solids & $\%$ Organics & EN 14346:2007 \\
\hline$\sum \mathrm{TPH}(\mathrm{C}<12+\mathrm{C}>12)$ & $\mathrm{mg} / \mathrm{kg}_{\mathrm{TS}}$ & EN 14039:2005 \\
\hline Benzo(a)antracene & $\mathrm{mg} / \mathrm{kg}_{\mathrm{TS}}$ & EN 16181:2018 or EN 15527:2008 \\
\hline Benzo(b)fluorantene & $\mathrm{mg} / \mathrm{kg}_{\mathrm{TS}}$ & EN $16181: 2018$ or EN $15527: 2008$ \\
\hline Benzo(j)fluorantene & $\mathrm{mg} / \mathrm{kg}_{\mathrm{TS}}$ & EN $16181: 2018$ or EN $15527: 2008$ \\
\hline Benzo(k)fluorantene & $\mathrm{mg} / \mathrm{kg}_{\mathrm{TS}}$ & EN 16181:2018 or EN 15527:2008 \\
\hline Pyrene & $\mathrm{mg} / \mathrm{kg}_{\mathrm{TS}}$ & EN $16181: 2018$ or EN $15527: 2008$ \\
\hline Crisene & $\mathrm{mg} / \mathrm{kg}_{\mathrm{TS}}$ & EN $16181: 2018$ or EN $15527: 2008$ \\
\hline Dibenzo(a,h)antracene & $\mathrm{mg} / \mathrm{kg}_{\mathrm{TS}}$ & EN 16181:2018 or EN 15527:2008 \\
\hline Naftalene & $\mathrm{mg} / \mathrm{kg}_{\mathrm{TS}}$ & EN 16181:2018 or EN 15527:2008 \\
\hline$\sum(\mathrm{PCB} / \mathrm{PCT})$ & $\mathrm{mg} / \mathrm{kg}_{\mathrm{Ts}}$ & EN $12766-1$ and EN $12766-2$ \\
\hline
\end{tabular}

terms of EC50 (\%vol/vol and \%w/w for aquatic and terrestrial tests respectively), which is the tested dilution of the test samples (with respect to the specific dilution media) generating $50 \%$ of the considered effect in the specific bioassay.

\subsubsection{Bioassays on terrestrial organisms}

- The test battery presented in Table 4 must be implemented on the ASR solid test samples prepared following the procedures described in Paragraph 3.4.1.

- The ranking of the sensitivity of the test battery listed in Table 4 is: Arthrobacter > Eisenia > Brassica.

- Each test is carried out following the instructions laid out in the specific standard listed in Table 4.

TABLE 2: List of parameters to be measured in aqueous test samples.

\begin{tabular}{|c|c|c|}
\hline Analytes & Unit of measure & Standards \\
\hline DOC & $\mathrm{mg} / \mathrm{L}$ & EN 1484:1997 \\
\hline TDS & $\mathrm{mg} / \mathrm{L}$ & EN 14346: 2007 \\
\hline Chlorides (as Cl) & $\mathrm{mg} / \mathrm{L}$ & EN ISO 10304-1:2009 \\
\hline Fluorides (as $\mathrm{Fl}$ ) & $\mathrm{mg} / \mathrm{L}$ & EN ISO 10304-1:2009 \\
\hline Sulphates $\left(\mathrm{as} \mathrm{SO}_{4}^{-}\right)$ & $\mathrm{mg} / \mathrm{L}$ & EN ISO 10304-1:2009 \\
\hline \multicolumn{3}{|c|}{ Metals and metalloids } \\
\hline Antimony & $\mathrm{mg} / \mathrm{L}$ & EN ISO 11885:2009 \\
\hline Arsenic & $\mathrm{mg} / \mathrm{L}$ & EN ISO 11969:1996 \\
\hline Barium & $\mathrm{mg} / \mathrm{L}$ & EN ISO 11885:2009 \\
\hline Cadmium & $\mathrm{mg} / \mathrm{L}$ & EN ISO 11885:2009 \\
\hline Chromium Total & $\mathrm{mg} / \mathrm{L}$ & EN ISO 11885:2009 \\
\hline Copper & $\mathrm{mg} / \mathrm{L}$ & EN ISO 11885:2009 \\
\hline Lead & $\mathrm{mg} / \mathrm{L}$ & EN ISO 11885:2009 \\
\hline Mercury & $\mathrm{mg} / \mathrm{L}$ & EN ISO 12486:2012 \\
\hline Molybdenum & $\mathrm{mg} / \mathrm{L}$ & EN ISO 11885:2009 \\
\hline Nickel & $\mathrm{mg} / \mathrm{L}$ & EN ISO 11885:2009 \\
\hline Selenium & $\mathrm{mg} / \mathrm{L}$ & EN ISO 11885:2009 \\
\hline Zinc & $\mathrm{mg} / \mathrm{L}$ & EN ISO 11885:2009 \\
\hline
\end{tabular}

TABLE 3: Concentration ranges on ASR solid samples that trigger the need to perform terrestrial bioassay. a - derived from European Council, 2004 and further amendments. b - derived from European Parliament and European Council, 2019.

\begin{tabular}{l|c:c}
\hline Substance & Unit of measure & Concentration range \\
\hline$\sum \mathrm{TPH}(\mathrm{C}<12+\mathrm{C}>12)$ & $\mathrm{mg} / \mathrm{kg}_{\mathrm{TS}}$ & $0.001 \leq \mathrm{x}<1,000$ \\
\hdashline Benzo(a)antracene & $\mathrm{mg} / \mathrm{kg}_{\mathrm{TS}}$ & $0.001 \leq \mathrm{x}<1,000$ \\
\hdashline Benzo(b)fluorantene & $\mathrm{mg} / \mathrm{kg}_{\mathrm{TS}}$ & $0.001 \leq \mathrm{x}<1,000$ \\
\hdashline Benzo(j)fluorantene & $\mathrm{mg} / \mathrm{kg}_{\mathrm{TS}}$ & $0.001 \leq \mathrm{x}<1,000$ \\
\hline Benzo(k)fluorantene & $\mathrm{mg} / \mathrm{kg}_{\mathrm{TS}}$ & $0.001 \leq \mathrm{x}<1,000$ \\
\hline Pyrene & $\mathrm{mg} / \mathrm{kg}_{\mathrm{TS}}$ & $0.001 \leq \mathrm{x}<1,000$ \\
\hline Crisene & $\mathrm{mg} / \mathrm{kg}_{\mathrm{TS}}$ & $0.001 \leq \mathrm{x}<1,000$ \\
\hdashline Dibenzo(a,h)antracene & $\mathrm{mg} / \mathrm{kg}_{\mathrm{TS}}$ & $0.001 \leq \mathrm{x}<1,000$ \\
\hdashline Naftalene & $\mathrm{mg} / \mathrm{kg}_{\mathrm{TS}}$ & $0.001 \leq \mathrm{x}<1,000$ \\
\hdashline$\sum$ (PCB/PCT) & $\mathrm{mg} / \mathrm{kg}_{\mathrm{TS}}$ & $0.0001 \leq \mathrm{x}<50^{\mathrm{b}}$ \\
\hline
\end{tabular}




\subsubsection{Bioassays on aquatic organisms}

- Test battery presented in Table 5 must be implemented on the ASR aqueous test samples prepared following procedures described in Paragraph 3.4.2.

- Ecotoxicological tests should be carried out within $72 \mathrm{~h}$ from the preparation of the aqueous test sample, which shall be stored in glass bottles with a minimal headspace at $(4 \pm 2){ }^{\circ} \mathrm{C}$.

- No pH adjustments of the test sample shall be carried out. pH of the mixture should be measured immediately at the beginning and at the end of the test.

- The ranking of the sensitivity of the test battery listed in table 5 is: Pseudokirchneriella > Daphnia magna > Vibrio Fischeri.

- Each test is carried out following the specific standard listed in Table 5.

\subsection{Classification criteria}

- ASR is classified as HP 14 if at least one of the performed bioassays resulted in an EC50 not compliant (i.e. strictly lower) than the concentration limits listed in Tables 4 and 5 for terrestrial and aquatic tests, respectively.

\section{CONCLUSIONS}

This paper proposes an experimental procedure for the HP 14 classification of ASR through ecotoxicological testing. In addition, this manuscript includes the founding principles behind the proposition.

TABLE 4: Recommended ecotoxicological test battery on terrestrial organisms. Rounded limits are suggested according to Hennebert (2018b) based on thresholds proposed in Hennebert (2018a) for HP14 classification of waste. Concentration limits are reported as dilution \% expressing dry mass of solid test sample on dry mass of specific dilution media, as required from the specific test.

\begin{tabular}{l:l:l} 
Organism & $\begin{array}{l}\text { Concentration limits } \\
\text { for HP 14 classification }\end{array}$ & Standards \\
\hline $\begin{array}{l}\text { Soil bacteria } \\
\text { (Arthrobacter } \\
\text { globiformis) }\end{array}$ & EC50 $<5 \%(\mathrm{w} / \mathrm{w})$ & ISO 18187:2016 \\
\hdashline $\begin{array}{l}\text { Plants } \\
\text { (Brassica rapa) }\end{array}$ & EC50 < 15\% (w/w) & EN ISO 11269- \\
\hdashline $\begin{array}{l}\text { Soil invertebrates } \\
\text { (Eisena fetida) }\end{array}$ & EC50 < $5 \%(\mathrm{w} / \mathrm{w})$ & ISO 17512-1:2008 \\
\hline
\end{tabular}

TABLE 5: Recommended ecotoxicological test battery on aquatic organisms. Rounded limits are suggested according to Hennebert (2018b) based on thresholds proposed in Hennebert (2018a) for HP14 classification of waste. Concentration limits are reported as dilution \% expressing volume of aqueous test sample on volume of specific dilution media, as required from the specific test.

\begin{tabular}{|c|c|c|}
\hline Organism & $\begin{array}{l}\text { Concentration limits } \\
\text { for HP } 14 \text { classification }\end{array}$ & Standards \\
\hline $\begin{array}{l}\text { Aquatic bacteria } \\
\text { (Vibrio Fischeri) }\end{array}$ & EC50 < 15\% $(\mathrm{vol} / \mathrm{vol})$ & EN ISO 11348-3 \\
\hline $\begin{array}{l}\text { Algae } \\
\text { (Pseudokirchneriel- } \\
\text { la subcapita) }\end{array}$ & EC50 < 10\% (vol/vol) & EN ISO 8692 \\
\hline $\begin{array}{l}\text { Crustaceans } \\
\text { (Daphnia magna) }\end{array}$ & EC50 < 10\% (vol/vol $)$ & EN ISO 6341 \\
\hline
\end{tabular}

The document includes technical detailed instructions for each step of the procedure, from the production of the laboratory sample to ultimate classification based on the comparison of the results of a battery of bioassays with a proposed set of concentration limits. Furthermore, the chemical and physical characterization is required for both solid test samples and aqueous test samples. These samples are obtained through the performance of a leaching test. The proposed ecotoxicological tests include 3 aquatic and 3 terrestrial tests. However, the need to perform terrestrial tests is triggered when concentrations of several non-soluble and non-leachable contaminants in the solid test samples are recorded within proposed concentration ranges.

The compliance with European Regulation for HP 14 classification is ensured through the reference to international technical standards derived from the EN ISO series for each step of the proposed procedure.

Through this paper, the authors aimed to share with the scientific community the principles of this procedure and their technical application on a specific waste stream, while providing a basis for the development of sound scientific procedures for HP 14 classification by testing for other types of wastes, classified as mirror entries in the EWC.

\section{REFERENCES}

CEN/TR 15310-1, 2006 - Characterization of waste - Sampling of waste materials - Part 1: Guidance on selection and application of criteria for sampling under various conditions.

Cossu, R., Fiore, S., and Lai, T. et al. 2014. Review of Italian experience on automotive shredder residue characteriza- tion and management. Waste Management 34:1752-1762. doi:10.1016/j.wasman.2013.11.014.

Cossu, R., Lai, T., 2015. Automotive shredder residue (ASR) management: An overview. Waste Manag. 45, 143-151. https://doi. org/10.1016/j.wasman.2015.07.042.

EN 12457-2, 2002 - Characterization of waste - Leaching - Compliance test for leaching of granular waste materials and sludges - Part 2: One stage batch test at a liquid to solid ratio of $10 \mathrm{l} / \mathrm{kg}$ for materials with particle size below $4 \mathrm{~mm}$.

EN 12457-2, 2004 - Characterization of waste - Leaching - Compliance tests for leaching of granular wastes materials and sludges - part 2: one stage batch test at a liquid to solid ratio of $10 \mathrm{l} / \mathrm{kg}$ for materials with particle size below $4 \mathrm{~mm}$ (without or with size reduction).

EN 14735, 2005 - Characterization of waste - Preparation of waste samples for ecotoxicity tests.

EN 14899, 2005 - Characterization of Waste - Sampling of waste materials - Framework for the preparation and application of a Sampling Plan.

EN ISO 11269-2, 2012 - Determination of the effects of pollutants on soil flora -- Part 2: Effects of contaminated soil on the emergence and early growth of higher plants.

EN ISO 11348, 2008 - Water quality - Determination of the inhibition effect of water samples on the light emission of Vibrio Fischeri (Luminescent bacteria test) -- Part 3: Method using freeze-died bacteria.

EN ISO 14780, 2017 - Solid biofuels - Sample preparation

EN ISO 15002, 2015 - Characterization of waste - Preparation of test portions from the laboratory sample.

EN ISO 6341, 2012 - Water quality - Determination of the inhibition of the mobility of Daphnia magna Straus (Cladocera, Crustacea) - Acute toxicity test.

EN ISO 8692-2, 2012 - Water quality -Fresh water algal growth inhibition test with unicellular green algae. 
European Commission, 2014. Commission Regulation (EU) No 1357/2014 of 18 December 2014 replacing Annex III to Directive 2008/98/EC of the European Parliament and of the Council on waste and repealing certain Directives Text with EEA relevance.

European Commission. 2000. Commision Decision of 3 May 2000 replacing Decision 94/3/EC establishing a list of wastes pursuant to Article 1(a) of Council Directive 75/442/EEC on waste and Council Decision 94/904/EC establishing a list of hazardous waste pursuant to Article 1(4) of C.

European Council, 2003. Council Decision of 19 December 2002 establishing criteria and procedures for the acceptance of waste at landfills pursuant to Article 16 of and Annex II to Directive 1999/31/EC

European Council, 2008. Council Regulation No 440/2008 of 30 May 2008 laying down test methods pursuant to Regulation (EC) No $1907 / 2006$ of the European Parliament and of the Council on the Registration, Evaluation, Authorisation and Restriction of Chemicals (REACH).

European Council, 2017. Council Regulation No 2017/997 of 8 June 2017 amending Annex III to Directive 2008/98/EC of the European Parliament and of the Council as regards the hazardous property HP 14 'Ecotoxic' 2006, 12-15.

European Parliament and European Council, 2008a. Directive 2008/98/ EC of the European Parliament and of the Council of 19 November 2008 on waste and repealing certain Directives [WWW Document]. Off. J. Eur. Union. URL http:// eur-lex.europa.eu/legal-content/EN/ TXT/?uri=CELEX:32008L0098 (Accessed 25.07.19).

European Parliament and European Council, 2008b. Regulation No 1272 of the European Parliament and the Council of 16 December 2008 on classification, labelling and packaging of substances and mixtures, amending and repealing Directives 67/548/EEC and 1999/45/EC, and amending Regulation (EC) No 1907/2006.

European Parliament and European Council, 2019. Regulation (EU) 2019/1021 of the European Parliament and of the Council of 20 June 2019 on persistent organic pollutants. URL https://eur-lex. europa.eu/legal-content/en/TXT/?uri=CELEX:32019R1021

Hennebert, P., 2018a. Proposal of concentration limits for determining the hazard property HP 14 for waste using ecotoxicological tests. Waste Manag. 74, 74-85. https://doi.org/10.1016/j.wasman.2017.11.048.
Hennebert, P., 2018b. Hazard classification of waste: review of available practical methods and tools. Proceedings CRETE 2018, Sixth International Conference on Industrial \& Hazardous Waste Management Chania - Crete - Greece; 4 - 7 September 2018 ISSN: 2241-3146.

Hennebert, P., 2019. the Sorting of Waste for a Circular Economy: Sampling When (Very) Few Particles Have (Very) High Concentrations of Contaminant or Valuable Element, in: Proceedings SARDINIA2019. CISA Publisher, Italy.

Hennebert, $\mathrm{P}$, van der Sloot, H.A., Rebischung, F., Weltens, R., Geerts, L., Hjelmar, O., 2014. Hazard property classification of waste according to the recent propositions of the EC using different methods. Waste Manag. 34, 1739-1751. https://doi.org/10.1016/j. wasman.2014.05.021

ISO 17512-1, 2017 - Soil quality - Avoidance test for determining the quality of soils and the effects of chemicals on behavior - Part 1: Test with earthworms (Eisenia Foetida and Eisenia Andrei).

ISO 18187, 2016 - Contact test for solid samples using the dehydrogenase activity of Arthrobacter globiformis.

Moser, H., and Römbke, J. (Eds), 2009. Ecotoxicological characterization of waste - Results and experiences of a European ring test. Springer Ltd., NewYork, USA.308 pp.

OECD, 2001. Number 29. GHS - ANNEX 10 Guidance on Transformation/Dissolution of Metals and Metal Compounds in Aqueous Media. OECD Ser. Test. Assess.

OECD, 2019. Number 23. Guidance Document on aqueous-phase aquatic toxicity testing of difficult test chemicals. OECD Ser. Test. Assess.

Pandard, P., Römbke, J., 2013. Proposal for a "Harmonized" strategy for the assessment of the HP 14 property. Integr. Environ. Assess. Manag. 9, 665-672. https://doi.org/10.1002/ieam.1447.

Pivato A., Beggio G., Raga R., Soldera V., 2019. Forensic assessment of HP14 classification of waste: evaluation of two standards for preparing water extracts from solid waste to be tested in aquatic bioassays. Environmental Forensics. 20, 275-285. DOI: https://doi. org/10.1080/15275922.2019.1630517.

Römbke, J., 2018. Testing of 24 potentially hazardous wastes using 6 ecotoxicological tests. Detritus 4, 4-21. https://doi. org/10.31025/2611-4135/2018.13745.

UNI EN 10802, 2013 - Rifiuti - Campionamento manuale, preparazione del campione ed analisi degli eluati (in Italian). 